\title{
PÍCAROS Y FANTASÍA, O UNA POSIBLE RECEPCIÓN CONTEMPORÁNEA DE LA SECUELA LAZARILLESCA DE AMBERES
}

\author{
José Antonio Calzón García \\ Universidad de Cantabria \\ https://doi.org/10.18778/8220-195-6.14
}

\begin{abstract}
Resumen
El artículo pretende realizar una relectura de la continuación del Lazarillo de Tormes publicada en Amberes en 1555 a partir de las codificaciones actuales del género fantástico, reformulando la lectura del texto -y en particular del episodio central de la novela, esto es, la metamorfosis de Lázaro en atún- desde el prisma y los referentes teóricos de la narrativa contemporánea, con vistas a replantear la consideración crítica hacia un texto muy poco estudiado y tradicionalmente ensombrecido por los logros revolucionarios del relato del que se hace deudor.
\end{abstract}

Palabras clave: Lazarillo, fantasía, Amberes, continuación, recepción.

\section{1.}

\section{Introducción. La fantasía y lo fantástico}

Enfrentarse al concepto de literatura fantástica supone asumir oxímoros y paradojas como la tautología inherente a una representación textual carente de "realidad exterior al lenguaje" (Todorov, 1982: 112) o la verosimilitud de un universo en el que se "muestra como algo posible lo que aparentemente consideramos 
imposible" (Herrero Cecilia, 2016: 18). Esta clase de juicios jalonan el discurso crítico en torno a un tipo de texto cuyo origen habría que situar en las coordenadas de la historia contemporánea, del siglo XVIII en adelante (Todorov, 1982: 197), con una muy especial incidencia durante el período romántico (Herrero Cecilia, 2016: 20).

Desde un punto de vista puramente pragmático, el género fantástico enfrenta al lector con el desafío de la transgresión de índole ontológica, llevándonos a vacilar ante un hecho que se presenta como real e imaginario al mismo tiempo, mediante la técnica de mostrar una realidad conocida, la nuestra, que de repente sufrirá una ruptura. Lo fantástico jugará a franquear ciertos límites inaccesibles en tanto no se recurre a él (Todorov, 1982: 187), remitiéndonos a un mundo de posibilidades imposibles.

De este modo, el género fantástico parece atentar contra la lógica aristotélica del universo binario, revitalizando el principio del tercio excluso al enfrentar al lector con la duda entre una explicación sobrenatural y otra natural de los acontecimientos. Así, el tránsito, nunca permanente, entre lo racional y lo irracional es llevado a cabo por el receptor desde un estado a caballo entre la inseguridad y la seducción, mediante una integración en el mundo de los personajes que no le aleja, sin embargo, de la percepción ambigua (Todorov, 1982: 41). Precisamente, el efecto de lo fantástico es tan efímero como la propia indeterminación de quien lo percibe, al comprender que se pone en tela de juicio "la existencia de una oposición irreductible entre lo real y lo irreal" (Todorov, 1982: 198).

En última instancia, la re-creación del universo fantástico estará siempre en manos del propio receptor, obligado a tomar partido, bien a favor de las leyes de la realidad, inamovibles, bien optando por una reformulación epistemológica del universo que se nos es mostrado (Todorov, 1982: 53). Lo fantástico no vendría marcado tanto por un nuevo ámbito referencial cuanto por la constatación, autorreflexiva, de la existencia de ese nuevo universo. En resumen, lo fantástico podría ser definido como "una percepción particular de acontecimientos extraños" (Todorov, 1982: 111), que termina por llevar, en ocasiones, al terreno 
de la literatura inquietante o desconcertante (Herrero Cecilia, 2016: 25), a partir de la percepción de un nuevo universo liminar que no acertamos a decodificar desde los patrones del es/no es aristotélico.

\section{2. \\ Entramados y redes en el universo fantástico}

El universo de lo fantástico parece deslizarse en el ámbito de la intertextualidad desde el momento en el que dialoga con lo real, en mayor o menor medida, al tiempo que abre posibilidades epistemológicas a otros mundos y otras lógicas. Desde este prisma, el recurso de lo figurado vuelve una y otra vez al discurso fantástico, quizás para recordarnos que lo sobrenatural nace del lenguaje, y a él regresa como mecanismo de justificación, siempre y cuando lo metafórico no suplante al valor representativo de la narración, sea esta real o no (Todorov, 1982: 99). Así, lenguaje y universo conocido se convierten en las dos cabezas de un constructo bicéfalo que tiende la mano tanto a referentes textuales conocidos como a mundos representados más o menos fieles respecto al universo que conocemos, en una sucesión de madejas y redes donde el juego, en última instancia, legitima la narración, sin caer por ello en lo absurdo (Todorov, 1982: 204). En este narrar, la figura del monstruo cobrará un especial protagonismo, en cuanto criatura perteneciente a otro mundo, signo al tiempo de una ausencia de referente o de una categoría donde pueda incluírsele (Todorov, 1982: 220).

En resumen, el discurso fantástico admite ser contemplado como una auténtica tela de araña en la cual mundo real y universo concebido se crean puentes una y otra vez, gracias a la mediación de un texto construido sobre los pilares de la intertextualidad o, si se prefiere, anclado en los basamentos de un tipo de narrativa que juega, por encima de todo, a crear, a partir de componentes referenciales que no resulten del todo ajenos al receptor. 


\section{La segunda parte de Lazarillo de Tormes, o cómo enfrentarse al requiebro de lo inesperado}

En 1555 veía la luz en Amberes un texto que reclamaba el derecho a erigirse como la primera continuación de las andanzas y desventuras de nuestro pícaro más famoso. La obra, retomando el final del texto original, nos presentaba a Lázaro sumergido en el célebre ménage à trois que cerraba la obra primigenia. Alentado por las ensoñaciones de unos amigos, el pícaro se envalentonará para participar en la guerra de Argel, sin saber que esto le llevará a lidiar con el naufragio del barco que le transportaba. Sorprendentemente, gracias al vino bebido, Lázaro no solo no muere, sino que se ve metamorfoseado en atún, llevando a partir de entonces auténtica vida de pez en compañía de sus nuevas amistades. Pero, por desgracia, las redes de unos pescadores le devolverán a su universo, viéndose así de nuevo reconvertido en humano y regresando a Toledo, donde comprobará ya sin asomo de duda cómo el lecho conyugal se ha mantenido caliente gracias a las lúbricas inquietudes del arcipreste. Incrédulo al principio, el sacerdote negará que el aparecido sea Lázaro, hasta que las semejanzas respecto a su antiguo mantenido le obliguen a aceptarlo sin asomo de duda. Entendiendo que allí ya solo sobra, irá Lázaro a Salamanca, lo que dará pie para concluir el libro con las batallas dialécticas académicas y con los lances de naipes del protagonista.

A la hora de analizar tan excéntrico texto, se han puesto sobre la mesa un sinfín de interpretaciones, en particular en lo que atañe al elemento nuclear, esto es, la metamorfosis de Lázaro y su vida con los atunes. Así, desde descarnada alegoría de la sociedad (Mascarell, 2011: 276) a metáfora de la conversión (Hasson, 2014: 95), pasando por posible roman à clef (Hasson, 2014: 96) o crítica a la corrupción de la corte y del ejército español (Piñero Ramírez, 1988: 27), casi cualquier tipo de etiqueta ha servido para encontrar sentido a la enigmática transformación del pícaro en pez y a las aventuras que en el universo marino le suceden. 
No obstante, llama poderosamente la atención el escaso interés hasta ahora por analizar per se el pasaje fantástico que se inserta en los cauces de una novela -y un género- paradigmáticamente realistas.

Más homogeneidad encontramos, sin embargo, en torno a los lapidarios juicios acerca de la calidad estética de la obra. Como apunta Hasson (2014: 95-96), ya en el siglo XVI se consideró la continuación del Lazarillo como "un texto bastardo, disparatado e indigno de ser leído", lo que llevó a la crítica a ocuparse "en fútiles comparaciones que terminaron afirmando la inferioridad de la secuela antuerpiense respecto al texto que pretende continuar". No obstante, y a pesar de que no se puede obviar sin más que una parte de los lectores coetáneos de esta continuación de 1555 no habría comprendido en absoluto la obra, quizá por su propia complejidad y por la estructura de miscelánea no bien resuelta, la edición del texto varias veces a lo largo de la segunda mitad del siglo XVI y su traducción pocos años después al inglés, francés e italiano atestiguan un interés inicial por la obra que terminó desembocando - tras su incorporación al Cathalogus librorum del inquisidor Fernando de Valdés en 1559- en varios siglos de olvido, no imprimiéndose el texto en España hasta mediados del XIX (Piñero Ramírez, 1988: 7 y 14-15). Y así, presentado siempre al amparo del libro original, y contemplado como un texto raro, extraño, especialmente por el episodio de la metamorfosis y de las aventuras atunescas, llegaría a las manos de Menéndez Pelayo (1978: 143), para sufrir ya sin cortapisas el tormento de la descalificación lapidaria, al afirmar el erudito que la novela "es de todo punto necia e impertinente, y el anónimo continuador dio muestras de no entender el original que imitaba. Convirtióle en una alegoría insulsa”. 


\section{Deudas y lazos en el Lazarillo antuerpiense. La cuestión de la intertextualidad}

Obviamente, las aventuras atunescas de nuestro pícaro más universal parten del relato anónimo de 1554, especialmente en lo tocante al primer capítulo (Mascarell, 2011: 272; Rodríguez López-Vázquez, 2014: 115), gracias a ese guiño servido por la edición de Alcalá, donde se promete al narratario dar cuenta de cualquier novedad futura sobre la persona del protagonista (Piñero Ramírez, 1988: 12), pero, lejos de incidir en su naturaleza picaresca, la crítica ha apuntado los débitos para con clásicos como $E l$ asno de oro (Mascarell, 2011), el episodio bíblico de Jonás y la ballena (Hasson, 2014: 98), el folklore tradicional (Piñero Ramírez, 1988: 24) o las novelas de caballerías (Piñero Ramírez, 1988: 45), por citar tan solo algunos ejemplos. En cualquier caso, no deja de llamar la atención la constante oscilación, a este respecto, entre la literatura de corte más o menos fantástico -e incluso maravilloso, si quisiéramos profundizar en la división- y la que sin vacilaciones se adscribe al ámbito de la narración realista. Todo ello no hace más que ahondar, en suma, en la problemática semántica del texto: ¿cuál es el universo referencial que configura la realidad representada por el Lazarillo antuerpiense?

\section{5. \\ Realidad y fantasía en la continuación de Amberes: la cuadratura del círculo}

A la hora de analizar la continuación anónima del Lazarillo, como se ha apuntado, son innumerables los guiños para con la obra original. Así, desde la réplica casi absoluta del final de la edición de Alcalá -“lo demás, con el tiempo, lo sabrá Vuestra Merced” (p. 
259)1- hasta la presencia de idéntico narratario -"Vuestra Merced estará, como he dicho, informado” (p. 133)-, pasando por las alusiones al ciego -"oraciones que del ciego mi primero amo aprendî" (p. 135)-, la relevancia del vino -"mi ciego, cuando en Escalona me dixo que si a hombre el vino había de dar vida había de ser a mí" (p. 138)-, la presencia tanto del arcipreste como de su mujer -“con la mi Elvira y mi amo el arcipreste” (p. 172)-, las referencias al ejercicio de la profesión de pregonero -"excepto pregonando los vinos, que hacía casi lo mismo" (p. 186)- o el aparente ascenso social y la vanagloria que su obtención comporta - "di gracias a Dios porque mis cosas iban de bien en mejor [...] ningún negocio de mucha o poca calidad se despachaba sino por mi mano y como yo quería" (p. 214)-, nada en la obra parece haber sido hecho sin estar con un ojo sobre el texto de 1554. Esto lleva, pues, a ponderar el peso del realismo a la hora de analizar el impacto de la obra primigenia sobre la secuela atunesca. En efecto, sobradamente conocido es el hecho de que el Lazarillo original pretendía no solo pasar por relato auténticamente real, sino producir en el lector la impresión de ser una narración verosímil, esto es, verificable (Mascarell, 2011: 275). Ahora bien, el juego de andar a caballo entre realidad y ficción, gracias a un anonimato de naturaleza epistolar que contribuía a sembrar aún más dudas, llevaba a enfrentarse a un modelo de lectura inédito hasta entonces. De igual modo, la historia autobiográfica de un pregonero no podía ser recibida como ficción, con lo que el novelista ofrecía más bien una "falsificación", un apócrifo, mejor que un anónimo (Rico, 1988: 31-32). No obstante, de cualquiera de las maneras, "no hay inconveniente, pues, en calificar el Lazarillo de realista [...] porque se nos ofrece como de veras escrito por un pregonero [...] lo que básicamente se presenta como si fuera real es el acto de lenguaje, el hecho de que el pregonero escriba una carta" (Rico, 1988:

1 Para evitar la prolijidad, y ante el significativo número de citas, optamos por mencionar tan solo la página correspondiente de la edición de la Segunda Parte del Lazarillo de Pedro M. Piñero Ramírez (Anónimo, Juan de Luna, 1988), cuya referencia completa se encuentra en la bibliografía final. 
46 y 79). En cualquier caso, obvio es que el esfuerzo por transmitir al lector un relato tan extraño como aparentemente real no debió de escapar al continuador del texto, ofreciendo una obra donde los guiños a la novela original chocaban contra el desafío de ver al protagonista convertido en atún. ¿Por qué mofarse, pues, de la técnica realista con una historia tan descabellada y absurda?

El texto antuerpiense, en efecto, ofrece como elemento nuclear una metamorfosis, explicable, a priori, por dos mecanismos diferentes. Por un lado, la transformación parece consecuencia de una suerte de intervención divina -"el Señor, por virtud de su pasión y por los ruegos [...] obró en mí un maravilloso milagro [...] y fue que [...] sentí mudarse mi ser de hombre [...] cuando me vi hecho pez" (p. 143)-, pero, por otra parte, la metamorfosis puede valorarse también como mera fantasía del protagonista, fruto de una desmedida ingesta de alcohol -"bebí tanto [...] que sentí de la cabeça a los pies no quedar en mi triste cuerpo rincón ni cosa que de vino no quedasse llena" (p. 136)-, la cual le conduciría al sueño, como pudiera atestiguar el elemento simbólico de la espada, que aparece justo al comenzar y concluir la experiencia atunesca, como una especie de vínculo entre la ensoñación etílica y el mundo real: "eché mano a mi espada, que en la cinta tenía, y comencé a baxar por mí mar abaxo" (p. 136); "los pescadores [...] me sacaron por la boca un braço y mano, con la cual yo tenía bien asida el espada, y me descubrieron por la cabeça la frente y ojos y narices y la mitad de la boca" (p. 235). De este modo, entre espada y espada asistiremos al desarrollo de toda una retahíla de aventuras bajo el mar, donde el mimetismo para con el universo humano será casi absoluto, reproduciendo espacios - "llegados al aposento del capitán" (p. 146)-, sentimientos - "la señora capitana le besó la cola dándole gracias de tan crecidas mercedes como muy bien supo" (p. 208)-, roles y relaciones -"llegamos a do mi amigo y los de su compañía tenían sus hijos y hembras" (p. 166)-, conflictos - "acordamos en el consejo de guerra que la señora capitana fuesse con nosotros" (p. 179)- o profesiones - "el executivo verdugo estaba dando gran prissa a la señora capitana se apartasse de allí y le dexasse hacer su oficio" (p. 189)-, por citar tan solo algunos ejemplos de un largo etcétera. De cualquiera de las maneras, este 
universo fantástico, deudor del mundo humano, invita a pensar en el esfuerzo por parte del autor a la hora de hacer de la sociedad atunesca un trasunto de la humana (Mascarell, 2011: 272), servida en bandeja gracias a una excepcional metamorfosis (Hasson, 2014: 98). Y así, de un realismo más o menos serio, en la obra seminal, pasamos a una fantasía con ribetes burlescos, en la cual la cuestión crucial que quedaría por dilucidar es si lo fantástico acaba en lo narrado o si, por el contrario, afecta también a la narración.

\section{6.}

\section{Conclusiones}

La Segunda Parte del Lazarillo, publicada anónimamente en Amberes en 1555, ha adolecido, en primer lugar, del silencio y la censura de siglos durante los cuales el peso de la obra primigenia no dejó margen para lecturas de la continuación carentes de prejuicios. En segundo lugar, la crítica actual, más centrada en las posibles fuentes, así como en la lectura en clave alegórica, ha dejado de lado todos los estudios relacionados con el análisis del discurso fantástico per se. Obviamente, el siglo XVI dista mucho aún de ser el período en el que dicho género eclosione, pero ello no tendría por qué ser óbice para un análisis desde la recepción de una obra que retoma de forma intencionada un relato marcadamente realista y lo inserta en un discurso donde el universo fantástico se convierte en uno de los pilares nucleares de la narración. En este sentido, las investigaciones sobre lo fantástico, ya desde Todorov (1982), han insistido en el papel del lector a la hora de interpretar relatos donde lo inesperado, lo sobrenatural, lo extraño o lo irracional irrumpe en un contexto altamente mimético respecto a la realidad que conocemos. La continuación antuerpiense del Lazarillo juega, de ese modo, con la baza de la obra seminal, sobre la que añade la vuelta de tuerca que supone la metamorfosis atunesca del protagonista, y ahí es donde el peso del lector se vuelve crucial, valorando si ha de recodificar su lectura del texto 
original, analizar en clave onírica todo el pasaje de la aventura marina o simplemente reconsiderar su propia noción de realidad. La intertextualidad, clave en el discurso fantástico, cobra en la Segunda Parte del Lazarillo un valor fundamental, conjugando con gran eclecticismo deudas evidentes, como las concomitancias con El asno de oro, con el cuento folklórico-maravilloso o con el Lazarillo original, con una desafiante originalidad que parece romper el discurso realista de un género picaresco en ciernes con una aventura fantástica basada en una metamorfosis a todas luces imposible en la obra de 1554.

Sin duda, queda mucho camino por andar al respecto, pero estamos seguros de que la continuación antuerpiense de las aventuras de Lázaro necesita ya con urgencia de estudios en profundidad que analicen el texto a la luz de la crítica sobre el discurso fantástico. No en vano, la perplejidad que ha causado la obra, a lo largo de los siglos -la cual ha derivado muchas veces hacia la censura-, parece responder a esa vacilación, desconcierto o indeterminación que sobrevuela los textos de corte fantástico, donde lo inesperado desafía los límites de lo que todos nosotros entendemos como realidad, retomando irónicamente, así, la estela de ese texto desafiante, revolucionario e incomprendido en su momento, titulado Lazarillo de Tormes.

\section{Bibliografía}

Anónimo (2014). Segunda parte del Lazarillo de Tormes, ed. Alfredo Rodríguez López-Vázquez. Madrid: Cátedra.

Anónimo y Luna, J. de (1988). Segunda Parte del Lazarillo, ed. Pedro M. Piñero. Madrid: Cátedra.

Hasson, O. (2014). "Hacia una lectura de la conversión en la Segunda Parte del Lazarillo (Amberes, 1555)”, eHumanista/Conversos, 2, 94-106.

Herrero Cecilia, J. (2016). “Sobre los aspectos fundamentales de la estética del género fantástico y su evolución desde lo fantástico «romántico» a los fantástico "posmoderno»". Cédille. Revista de estudios franceses, 6, 15-51. 
Mascarell, P. (2011). "Lazarillos y metamorfosis. Estudio de las relaciones entre El asno de oro, el Lazarillo de Tormes y su Segunda parte". Lemir, 15, 271-284.

Menéndez Pelayo, M. (1978). Historia de los heterodoxos españoles. Madrid: BAC.

Piñero Ramírez, P.M. (1988). "Introducción”, en Segunda Parte del Lazarillo. Madrid: Cátedra, 7-122.

Rico, F. (1988). “Introducción”, en Lazarillo de Tormes. Madrid: Cátedra, 13-136.

Todorov, T. (1982). Introducción a la literatura fantástica. Barcelona: Ediciones Buenos Aires. 